\title{
Vorbemerkung zur vierten Lieferung
}

Leider kann ich erst jetzt die vierte Lieferung des Kommentars vorlegen. Der - mit den Studentenzahlen - wachsende Umfang der Lehrverpflichtungen und eine Fülle sonstiger Aufgaben behinderten die Arbeit. Die Neugestaltung des Agentenrechtes erschwerte die Darstellung dieser umfassenden und wichtigen, in das Erläuterungswerk von vornherein einbezogenen Materie. Ein besonderes Sachregister am Schluß der vierten Lieferung soll - neben den systematischen Übersichten S. 535-536, 550-551, 588, 610-615 - die Auffindung der gesuchten Abschnitte erleichtern.

Die fünfte Lieferung wird den ersten Band abschließen, der zweite Band des Werkes wird der Schadensversicherung und einzelnen Versicherungszweigen gewidmet sein. Da es sich für mich als undurchführbar erweist, alle Teile des Buches allein zu schreiben, habe ich für die Bearbeitung einzelner Versicherungszweige Mitarbeiter gewonnen, und zwar

für die Sachversicherung, insbesondere Feuerversicherung Prof. Dr. Reimer Schmidt,

für die Kraftverkehrsversicherung Senatspräsident z. Wv. Rechtsanwalt Gerhard Erich Fromm,

für die Lebensversicherung Dr. Rolf Magnusson,

für die Krankenversicherung Oberlandesgerichtsrat Dr. Paul Wriede.

So kann davon ausgegangen werden, daß künftig die Lieferungen des Kommentars in schnellerer Folge herauskommen.

Die Darstellung des Rechtes der einzelnen Versicherungszweige wird in neuartiger Form derart erfolgen, da $B$ in systematischer Ordnung jeweils sowohl das Gesetzesrecht als auch die Versicherungsbedingungen erläutert werden. Dás Recht der öffentlichrechtlichen Versicherung wird berücksichtigt werden, desgleichen wie bisher - das Material aus Rechtsprechung und Schrifttum in angestrebter Vollständigkeit.

Berkeley/Kalifornien, 30. September 1957

Hans Möller

\footnotetext{
Abkürzungen

Die Abkürzungen für die gebräuchlichsten Allgemeinen Versicherungsbedin. gungen (AVB) sind eingeführt in der Einleitung Anm. 20 (Lieferung 1).

Das wichtigste Schrifttum ist mit der benutzten Zitierweise angeführt in der Einleitung Anm. 39 (Lieferung 1). - Ist ein Werk mit dem Zusatz a. a. O. zitiert, so ist der genaue Fundort aus den Schrifttumsangaben des betreffenden Abschnitts zu entnehmen.

Ferner bedeuten: V = Versicherung, Ver $=$ Versicherer, Vmer $=$ Versicherungsnehmer, Vter $=$ Versicherter.

Ein ausführliches Abkürzungsverzeichnis wird der letzten Lieferung beigefügt sein.
} 